\title{
Cultur@s juvenis, identid@des e Internet: questões atuais*
}

\author{
Elisabete Maria Garbin
}

Universidade Federal do Rio Grande do Sul, Faculdade de Educação

\section{Navega comigo? Alguns apontamentos sobre Internet}

Ligo a televisão num sábado qualquer e assisto, num canal aberto, a um programa ${ }^{1}$ destinado ao público juvenil, que trata de um assunto da moda entre jovens ${ }^{2}$ conectados na Internet: os $b \log ^{3}{ }^{3} .$. Ao mesmo

* Agradeço a Rosa Maria Hessel Silveira, Marisa Vorraber Costa, Letícia Richthofen de Freitas e Ana Teresa Gotardo pelas leituras e sugestões para a organização deste artigo.

${ }^{1}$ Refiro-me ao programa regional semanal "Patrola", destinado ao público juvenil, veiculado pela RBS TV aos sábados, canal aberto da Rede Globo de Televisão, que tem como uma de suas características a informalidade.

${ }^{2}$ Embora consciente do viés sexista da Língua Portuguesa, que usa o gênero gramatical masculino para referir tanto mulheres como homens, optei por utilizar tal opção lingüística por questões de facilidade de leitura.

3 “"Blog é palavra derivada de weblog - ferramenta na Internet que permite qualquer usuário se cadastrar e ter um espaço próprio para escrever o que quiser. Weblog, vulgo 'blog', consiste em um tempo em que assisto a um misto de falas e imagens coladas com uma rapidez imensa, pergunto-me: desde que me debrucei na tentativa de escrita deste artigo, quantas novidades já foram veiculadas sobre Internet? Quantas notícias li, tanto em jornais impressos quanto virtuais, sobre a Internet e culturas juvenis? ${ }^{4}$

diário onde os registros cotidianos podem ser inseridos na forma de notícias, literatura, análises etc., sobre os mais diversos temas. Existem blogs sobre rock'n'roll, futebol, política, comunicação, tecnologia, religião, artes, em suma, qualquer pessoa pode registrar o que desejar neste espaço. O blog, por ser uma espécie de 'veículo de comunicação pessoal', tem como característica a informalidade". Ver o blog http://www.bigbiz.com.br/newmedia/ 041102.htm, assinado por Paulo Henrique Ferreira.

${ }^{4} \mathrm{O}$ termo culturas juvenis (Youth Cultures) está sendo usado neste artigo como um conjunto de formas de vida e valores característicos e distintos de determinados grupos de jovens, a maneira como tais experiências são expressas coletivamente mediante a construção de seus estilos de vida distintos, localizados, fundamentalmente em seu tempo livre ou em espaços de interstício da vida profissional (Feixa, 1999). 
Abro o jornal impresso do dia e leio uma nota: Iraquiano conta seu drama em site da Internet (Jornal Zero Hora, 25 mar. 2003). A notícia refere-se aos registros de um iraquiano, sob o nickname Salam Pax, ${ }^{5}$ que em árabe e em latim quer dizer "Paz", o qual, depois de alguns dias sem acesso à Web, ${ }^{6}$ volta a fazer registros em seu blog sobre a vida diária em uma cidade sob bombardeio americano, blog esse que está sendo acessado por milhões de usuários de Internet do mundo inteiro interessados em seu drama cotidiano. Pergunto-me novamente: até este meu artigo ser publicado, quantas outras (tristes) mudanças ainda teremos? Acredito que não haja campo temático nos dias atuais que se modifique com tanta rapidez... Então me questiono: como escrever sobre este assunto sem senti-lo "defasado" antes mesmo de abordá-lo, ainda que provisoriamente?

Parto da premissa de que a Internet não pode mais ser vista como um local apenas de troca, de busca de informações ou ainda de encontros entre pessoas, mas, também, como um local de produção de conhecimento, e relembro a afirmação de Stuart Hall:

Nossa participação na chamada Internet é sustentada pela promessa de que ela nos possibilite em breve assumirmos ciberidentidades - substituindo a necessidade de algo tão complicado e fisicamente constrangedor como é a interação real. (Hall, 1997, p. 23)

$\mathrm{O}$ autor fez a afirmação acima dentro de um exame da centralidade da cultura ${ }^{7}$ e das transformações da

\footnotetext{
${ }^{5}$ Vide blog http://dear_raed.blogs-pot.com.

${ }^{6}$ Estou usando neste artigo os substantivos Rede, Internet e
} Web como sinônimos.

${ }^{7}$ Nos estudos culturais, a noção de cultura é analisada por Hall de duas maneiras: no sentido substantivo, que é o entendimento que temos do "lugar da cultura na estrutura empírica real e na organização das atividades, instituições e relações na sociedade", e no sentido epistemológico, que, segundo o autor, trata da "virada cultural" que "passou a ver a cultura como uma condição constitutiva da vida social, ao invés de uma variável dependente vida local e cotidiana na constituição da subjetividade e da própria identidade. Tal citação me endereça novamente aos blogs: a febre do momento entre jovens, adultos... Em audiência ao programa televisivo a que me referi antes, sou informada de que foi da cidade de Viamão, no Rio Grande do Sul, que surgiu a primeira blogger brasileira. Mas o que vem a ser afinal, um(a) blogueira $(o)$ ? É aquele jovem, adulto que tem um computador conectado à Internet e que substitui seu "diário", objeto tradicional, quase exclusivo do gênero feminino, às vezes fechado à chave, por um weblog, que hoje ocupa bits e bytes de computadores e é usado tanto por garotos quanto por garotas. Entretanto, seus registros não se limitam a "decepções amorosas" ou "grandes segredos" próprios da adolescência, e sim, abrangem uma enorme gama de temas. Um weblog pode ser individual (se uma senha for utilizada) ou coletivo (fica na web para quem quiser acessar, ler e deixar recados...). Os assuntos de um blog variam desde rotinas cotidianas do blogueiro como "hoje estou triste porque meus pais brigaram", até questões de ordem profissional, como "perdi meu emprego mas to com outro na boca". ${ }^{8}$ O que leva um jovem a optar por escrever sobre suas mágoas, alegrias, planos, num diário virtual, abrindo-o a outras leituras, ao invés de escrever num diário impresso particular ou conversar face a face com amigos ou colegas? Estaremos vivendo a era da espetacularização da intimidade? Da derrocada das fronteiras do público e do privado?

Efetivamente, a velocidade com que a mídia eletrônica se transforma está fazendo com que pessoas e discursos estejam em muitos lugares ao mesmo tempo, distâncias sejam abreviadas, imagens e sons circulem vertiginosamente, capitais se reúnam, pessoas se "aproximem" virtualmente e, por que não dizer,

[...] 'virada cultural' essa que está intimamente ligada a esta nova atitude em relação à linguagem, pois a cultura nada mais é do que a soma de diferentes sistemas de classificação e diferentes formações discursivas aos quais a língua recorre a fim de dar significado às coisas" (Hall, 1997, p. 28-29).

\footnotetext{
${ }^{8}$ Excertos extraídos de blogs coletivos da Rede.
} 
"realmente". A isso Hall (1997) denomina de "deslocamentos". Deslocamentos aqui relacionados com o fato de que o mesmo artefato, o mesmo discurso ${ }^{9}$ pode se deslocar de modos diferentes, ao mesmo tempo, e estar em vários lugares. A mídia eletrônica se apresenta como um avanço tecnológico capaz de modificar nosso comportamento, com um discurso que se materializa em novas condições de possibilidades, em novos espaços e em novas formas que ele assume. Muitos de nós estamos sendo re-constituídos por essas variadas formas discursivas que usamos na Rede e que também são usadas para nós. Como observa Du Gay (apud Hall, 1997, p. 18):

[...] a nova mídia eletrônica não apenas possibilita a expansão das relações sociais pelo espaço e pelo tempo, como também aprofunda a interconexão global, anulando a distância entre as pessoas e os lugares, lançando-os em um contato intenso e imediato entre si, em um "presente" perpétuo, onde o que ocorre em um lugar pode estar ocorrendo em qualquer parte. [...] Isto não significa que as pessoas não tenham mais uma vida local - que não mais estejam situadas contextualmente no tempo e no espaço. Significa apenas que a vida local é inerentemente deslocada - que o local não tem mais uma identidade "objetiva" fora de sua relação com o global.

Essa tendência à homogeneização, anunciada por Hall (1997, p. 19), necessita mais do que nunca de "diferenças", de "novas identificações". Então, ao invés de um sincretismo que funde manifestações culturais numa só - a chamada cultura global da mídia - teríamos a criação de novas alternativas, não reducionistas e sim pluralistas e multifacetadas. Não posso deixar de evocar aqui Canclini (1998), quando este assinala que não basta saber que os discursos nos chegam de diferentes formas e de diferentes lugares, mas devese considerar que:

${ }^{9} \mathrm{O}$ termo discurso, neste artigo, está sendo abordado como as formas pelas quais as representações e convenções da linguagem produzem significados culturais (Broker, 1998, p. 66-67).
[...] se a intersecção do discurso "midiático" com outros mediadores sociais gera um campo de efeitos e esse campo não é definível só do ponto de vista da produção, conhecer a ação das indústrias culturais requer explorar os processos de mediação, as regras que regem as transformações entre um discurso e seus efeitos. (p. 263)

No meu entendimento, a Internet reúne três campos que pareciam distintos uns dos outros até o advento e socialização da $W e b$, que são a cultura, a comunicação e a informação, ou seja, as fronteiras entre estes três temas foram quebradas, desapareceram. A própria palavra escrita, a fala, as imagens fixas e as imagens em movimento, a música, os sons variados, enfim, tudo se encontra reunido na Rede. A Internet tornou-se um setor de ponta da economia globalizada, sendo que a mídia hoje pertence a grandes grupos internacionais. Há, por exemplo, grupos de mídia como o Portal de Internet AOL Time Warner (American Online) e a rede de televisão CNN (Cable New Network), que são, de certa forma, atores principais da globalização, visto que a globalização é também a "globalização" dos meios, haja vista que a AOL e CNN são do mesmo grupo midiático global (Time Warner). Em um mundo onde as informações se multiplicam, explodem e, muitas vezes, acabam por nos constituir, tomamos as idéias "emprestadas" e as reorganizamos, sem saber exatamente a sua origem nem a quem pertenciam, porque estão desterritorializadas. A própria noção de "autoria" na Rede é fluída e instável. Alguns estudiosos afirmam que textos virtuais e hipertextos perderam seus autores principais e são escritos a muitas mãos; outros defendem a autoria primeira, a legitimada pela academia impressa. De qualquer sorte, estes são temas instigantes e certamente deverão ser pauta ainda de muitas discussões.

\section{Estar aqui, estar lá... apagamento de fronteiras?}

É consensual que a rede revolucionou as noções tradicionais de distância entre as pessoas. A situacionalidade geográfica entre os internautas parece, em princípio, não importar, e este fenômeno também se 
relaciona com a globalização, que é muitas vezes associada a imperialismo cultural, fato discutido por O'Sullivan et alii (1997), que observam: "o processo de globalização deve distinguir-se do processo de imperialismo cultural pois se trata de um conceito mais complexo e totalizante, organizado e previsível em seus efeitos" (p. 168). Os autores registram que o desenvolvimento de uma "cultura global" tem resultado de "grandes trocas entre mercados e corporações multinacionais, de tecnologias de comunicação e midiáticas bem como os sistemas mundiais de produção de consumo" (idem, ibidem). Hall, por sua vez, argumenta que o termo "globalização" remete a processos de escala global que atravessam fronteiras, integrando-se e interconectando-se em comunidades, combinando espaços e tempos, provocando um "distanciamento" da idéia clássica de sociedade ordenada e delimitada. As comunidades virtuais estabelecidas através da Internet se inserem nessa malha de globalização, a qual permite que jovens de culturas distintas tornem-se onipresentes na Rede, falando sobre músicas de todo mundo, por exemplo. Esses "fluxos culturais entre as nações e o consumismo global criam possibilidades de 'identidades partilhadas"' (Hall, 1998, p. 74). Eé na leitura de pequenos excertos das conversas que esse jogo de desterritorialização pleno de armadilhas se torna mais vivo:

\section{Excerto $n^{o} 1$, extraído do Portal UOL/março $2003^{10}$}

(00:28:37) FaeL fala para GIRL*ANGEL: o pessoal ai nao tem preconceito por vc ser brasileira:? ou vc eh amaricana?

(00:29:16) GIRL*ANGEL fala para FaeL: naum eles adoram brasileiras!!tem um clip falando so do brasil!!!

(00:29:58) GIRL*ANGEL fala para FaeL: ves ai do brasil viram??

${ }^{10}$ Todos os excertos de chats gravados, aqui apresentados, são absolutamente fiéis à forma como foram digitados pelos internautas, preservando-se abreviaturas, palavrões, eventuais erros ortográficos.
(00:30:21) FaeL fala para GIRL*ANGEL: legal, eh q o pessoal as vezes pensa, mas foi oq meu amigo o pessoal nem se liga $\mathrm{mt}$, so alguns.... vc mora ai ha qnt tempo?

(00:38:32) GIRL*ANGEL fala para FaeL: E Q EU TO NO ICQ FALANDO COM MEU TIO AI DO BRASIL!!

(00:40:36) guigo fala para **sou timida**: vc é japonesa?

Excerto $n^{\circ} 2$, extraído do Portal TERRA/maio 2001

Metaleira! 20:48:58 fala com metal: de onde? stereolab 21:19:00: Porra, nem lembro mais... hehe... Eu dizia pela terceira vez que tc de Recife...hehe stereolab 21:20:12 fala com Smith: Blz. E tu, tc de onde? Smith 21:21:29 fala com stereolab: eu tb já disse! de Brasília

Metaleira! 20:34:31 fala com sepultura: bagé

sepultura 20:35:1 fala com Metaleira! sou da alegrete

Excerto $n^{\circ}$ 3, extraído do Portal UOL/maio 2001

(23:34:32) CINTHIAZINHA fala para 27/08/1984: onde vc mora

(23:35:39) 27/08/1984 grita com CINTHIAZINHA: PRAIA GRANDE SP

(23:41:39) Slash ${ }^{\circledR}$ grita com TwiggyRamirezFuck*: ONDE VC MORA?

(23:42:19) TwiggyRamirezFuck* grita com Slash®: No Rio porque?

(23:46:20) Dark Metarmofose fala para shirley_SP: De onde está tc?

(23:46:49) Dark Metarmofose fala para shirley_SP: Ops! Tá na cara! SP!

(23:58:29) FRAJOL@ fala para CINTHIAZINHA: GOIANIA (GO)

(00:00:02) Pri21 responde para Billy Corgan: Santos $\mathrm{e} \mathrm{vc}$ ?

(00:00:15) Billy Corgan grita com Pri21: Sampa, capital.

(00:11:45) Patricia fala para Thurston Francis: Sampa - Vl.Aricanduva 
(00:14:28) Thurston Francis fala para Patricia: Moro perto do autodromo de Interlagos

(00:15:35) \$henanigan\$ grita com beato salu: RIO DE JANEIRO

(00:20:45) Thurston Francis fala para Billy Corgan: Perto do Sondas da Cidade Dutra

(00:31:44) Rayna Foss Rose fala para ShEnAniGaNs: Eu sô do Rio mulé!

(00:33:30) Rayna Foss Rose fala para ShEnAniGaNs: Copacabana...C é do Rio???

(00:37:02) FRAJOL@ grita com TODOS: ALGUEM DE GOIANIA AQUI ???

Uma das principais características da Internet o apagamento das distâncias geográficas - parece cada vez mais se entranhar no mundo digital. Conforme Negroponte (1995), a distância significa cada vez menos neste mundo e a possibilidade de uma conversa sem imagens reais da visão e da audição, mas em tempo simultâneo, poderia apontar para a fluidez potencial da invenção de identidades. Entretanto, minha vivência permanente na Rede, em chats, em listas de discussão, em sites, assim como a análise dos materiais sobre os quais me debrucei para a escrita de minha tese, ${ }^{11}$ também aponta para restrições relacionadas aos próprios códigos utilizados nas salas, assim como as ligadas aos assuntos, à requisição de alinhamento no grupo ou seu distanciamento em relação a ele. Assim, é preciso ressaltar que - mesmo "desterritorializadas" e virtuais - muitas conversas nos chats emulam certos jogos típicos de uma conversa "real", que transcorrem como se os internautas estivessem ao vivo e não houvesse barreiras entre o virtual e o real. É o caso dos trechos anteriormente citados, em que as reiteradas perguntas sobre "de onde você tecla (tc)" apontam não para o fortalecimento de uma identidade regional, mas para a manutenção de tópicos de conversa descontraída e próxima.

11 Trata-se da tese de doutorado, intitulada www.identidadesjuvenis.com.br - um estudo de chats sobre música da Internet (Garbin, 2001).

\section{Linguagem internáutica: conversas sem sentido?}

Escrever é fácil. Você começa com uma maiúscula e termina com um ponto final. No meio, coloca idéias.

(Pablo Neruda) ${ }^{12}$

Penso ke eh momento d abordar 1 pouko (escrita internáutica da autora do presente texto) a linguagem/ escrita internaútica. Antes, porém, não pude deixar de colocar a epígrafe acima, de Pablo Neruda, que, de certa forma, vejo "linkada" à questão da escrita juvenil na Internet. Ao visitar outro blog, deparei-me com o seguinte trecho registrado pelo jovem de nick Dimitri:

Compartilho convosco hoje (isso mesmo, vosco! descobri que mais de uma pessoa lê essa parada aqui) uma citação que encontrei navegando por um blogg desses da vida: "Escrever é fácil. Você começa com uma maiúscula e termina com um ponto final. No meio, coloca idéias" (Pablo Neruda) Após ler, num primeiro momento comecei a divagar sobre o tema, mais ou menos assim: - Porra, mas comé que o cara, meu irmão esse cara viajou, existe isso não, muito do caralho, porra sério mermo....... Assim sempre respeitei, mas Neruda nunca foi dos meus poetas favoritos, isso porque apesar de geniais, seus poemas só têm um tema: o amor. Mas depois dessa citação......acho que é hora de rever conceitos. ${ }^{13}$

O desabafo do internauta parece expressar a preocupação dos jovens com o "contéudo" da escrita, seja ela na Rede, em seus poemas, em seus blogs, webzines, cadernos de escola, redações... Afinal, o que é mais importante da Rede: comunicar-se ou escrever dentro das normas e regras básicas de uma norma lingüísti-

${ }^{12}$ Excerto do livro de poemas de Pablo Neruda, Crepusculario, publicado em 1923 em espanhol, extraído do Blog http:// www.inagaki.blogger.com.br/2002_10_01_archive.html. Para ler mais: <http://sonhando.no.sapo.pt/sonho33.html>.

${ }^{13}$ Excerto extraído do blog http://mentirassinceras.blogspot.com/ 2002_11_03_mentirassinceras_archive.html. 
ca? Não tenho respostas e acredito que elas sejam difíceis, até porque a lingüística e a sociolingüística já fizeram desmoronar as paredes entre "certo" e "errado". Trata-se apenas de mais uma linguagem com características especiais, adequadas à sua função, como são todas as outras. Minha tese é a de que esta escrita "tão diferente", "agressiva" e "pobre" - para alguns professores de língua portuguesa, críticos(as) de plantão, principalmente aqueles mais arraigados a questões da norma lingüística, que freqüentemente têm declarado "guerra" à escrita abreviada utilizada na Internet - não é uma ameaça aos tradicionais adjetivos escolares de escrita. Tal escrita, abreviada, sincopada, com repetição de letras, repetição de palavras, com códigos próprios dos internautas, recheada de emoticons $^{14}$ que reforçam os sentimentos, não é uma "evolução" das outras escritas, e sim uma outra forma de escrita adaptada às peculiaridades de quem é usuário da Internet: o tempo virtual, a velocidade, e todas as suas principais formas e características. ${ }^{15}$

Nos chats se "fala", se "escreve", se "grita", se "chora", se "canta", enfim, há toda uma manifestação discursiva que se transforma em marcadores escritos. Sem dúvida, trata-se de uma "conversa teclada", que

${ }^{14}$ Também é característico da linguagem dos chats a criação de novos códigos, como o uso de emoticons, que se juntam a essa "fala-escrita" de modo a reforçar a expressividade dessa "fala", procurando "mostrar" sentimentos, emoções etc. Apresento alguns dos emoticons mais utilizados na Rede:

\begin{tabular}{|c|c|}
\hline :-O Atônito & :-) Sorrindo \\
\hline :-* Beijando & :-D Gargalhando \\
\hline :-P Mostrando a língua & ;-) Piscando \\
\hline$:-1$ Indeciso & :-( Triste \\
\hline :-\# Meus lábios estão selados & :'-( Chorando \\
\hline$: 1 \quad$ Nervoso & :-@ Gritando \\
\hline \multicolumn{2}{|l|}{ \}\}\}\}\}\}:-) Cabelo grande } \\
\hline \multicolumn{2}{|c|}{ E mais e mais se criam a cada dia, a cada "teclada". } \\
\hline${ }^{15}$ Ver reportagem veiculada no & suplemento ZH Escola do \\
\hline
\end{tabular}

resume uma nova articulação entre as linguagens orais e escritas, resultando das interações desenroladas entre os jovens freqüentadores dos chats. A seguir, alguns excertos que ilustram as afirmações citadas:

\section{Excerto $n^{\circ} 4$, extraído do Portal UOL/março 2003}

(23:37:37) doidinho jp fala para Lara: aki ten peruano boliviano coreano ten muito estrangero

(23:37:42) Dani $=^{\wedge} .^{\wedge}=$ fala para Gato_Barra_ICQ: depend (23:38:03) Werewolf grita com $^{\wedge} \mathrm{A}^{\wedge} \mathrm{nJo}^{\circledR}{ }^{\circledR e B e L d E}$ : vc eh satanico?

(23:38:26) Dani $=^{\wedge} .^{\wedge}=$ fala para Gåtø Đë $\emptyset$ lhøs äzüis: tc d ond? (23:38:27) óGatinho_só do cs fala para P@ty: ̃̃

(23:39:38) Anjo Sedutor flerta com gabi: deiche ele pra la e vamos tc!!!!!!!!!!!!!!!!!!!!!!!!!!

(23:39:44) Gato_Barra_ICQ fala para Dani $={ }^{\wedge} .^{\wedge}=:$ kd vc ?????

(23:40:04) doidinho jp fala para Lara: e canal japá e mo chato

Concordo com Silva (2000a) quando este argumenta que é apenas por meio de atos de fala [no caso, realizado através da escrita internáutica] que instituímos a identidade e a diferença como tais, ou seja, "elas são o resultado de criação lingüística" (p. 76), porém friso que, se no caso da Internet isso se confirma globalmente, na vida "real" a identidade também é fabricada com roupas, modos de andar, gestos corporais etc. Seria redutor afirmar que as identidades juvenis são apenas resultados de criação lingüística...

Numa sala virtual não há como se ver o aspecto físico do interlocutor - a não ser através do uso de câmeras de vídeo especiais para Internet (webcam) ou troca de fotos scaneadas pelo $\mathrm{ICQ}^{16}$ ou $e$-mails; na

${ }^{16}$ ICQ Inc.- antigo sucessor da Mirabilis Ltd., programa que foi criado por dois jovens israelenses em 1996 e vendido em 1998 por U\$ 270 milhões ao provedor gigante norte-americano America Online; programa que, além das "falas" (em mais de 20 línguas) em tempo real, pode adicionar voz através de arquivos ou conversas telefônicas e imagens às mensagens instantâneas. Pela 
vida "real", as identificações entre as subculturas dos jovens podem ser operadas através do modo de vestir, de falar, do uso de acessórios, da adoção de comportamentos e gestos [com maior ou menor agressividade], da exibição de itens de consumo, das marcas no corpo etc. Contudo, tentativas de materialização física e identificações tribais podem ser vislumbradas numa conversa entre jovens, como mostra o excerto a seguir:

Excerto $n^{\circ} 5$, extraído do Portal UOL/março 2003

(00:22:11) GIRL*ANGEL fala para FaeL: tenho cabelos castanhos e lizos, morena clara, olhos verdes e etc e vc?

(00:24:15) FaeL fala para GIRL*ANGEL: eu tb prefiro so ficar, mt novo pra ficar me prendendo demais, so se gostar mt da garota

(00:19:31) !GaTa IrAdA!^.^ fala para Maclanthuei: tenho cabelos e olhos catanhos,com 1,69 e 45kg,corpo definido e muito gatinha e vc?

(00:19:42) L.v.i fala para GATO LINDOO DOS OLHOS AZUIS: agorz cehgou, vou ver

(00:19:43) FeRnAnDiNhO fala para **ROCK GIRL**ICQ: agorta clica na seta da direita denovo...vai ver um loirinho tocando guitarra e cantando de blusa preta meio aberta

(00:20:06) GATO LINDOO DOS OLHOS AZUIS fala para L.v.i: VC VIU?????? COMO EU ESTAVA NA FOTO???????? DESCREVA!!!!!!!!!!!!!!!!A FOTO!!!!!!!!!!!!!

(00:20:29) Dany fala para RaFa: 1,65, morena clara, olhos castanhos.

(00:20:29) Maclanthuei fala para !GaTa IrAdA!^.^: Q gata!1,75,63 kg,branco,cabelos negros e lisos e olhos azuis profundamente irresistiveis, o q acha??

(00:25:06) GIRL*ANGEL fala para FaeL: vc e loiro de olhos azuis e eu morena clara de olhos verdes

pronúncia, o nome "ICQ" vem da pronúncia de I seek you ou, em bom português, "te procuro". O objetivo do ICQ é contatar em tempo real amigos internautas que estão conectados na Rede, não importa em que lugar do mundo, nem que língua falem.
(00:25:30) FaeL fala para GIRL*ANGEL: eh a combinaçao perfeita, se nao ia ficar mt igual

(00:25:41) FaeL fala para GIRL*ANGEL: mas se vc quiser pinto meu cabelo e ponho lentes

(00:34:03) suellen fala para namorado perfeito: to $\mathrm{cm}$ uma blusa branca e calca jeans e vc?

(00:37:31) Maclanthuei fala para @ LINDINHA: Q gata......quer saber como eu sou??

Os excertos acima ilustram minha suposição de que as identidades juvenis não são constituídas somente através dos discursos, dentro dos discursos. No caso dos bate-papos virtuais, a particularidade do anonimato permite que jovens se inventem também nas suas descrições físicas. É comum, numa navegada num chat, nos depararmos com auto-descrições que parecem não corresponder ao interlocutor. Embora correspondam às características socialmente tidas como atraentes, adequadas e charmosas, na vida real, a aparência física, o modo de vestir, de falar, abrem a possibilidade, a priori, para o estabelecimento de vínculos (ou não) entre as pessoas, o que não é condição sine qua non na Rede. Não estou querendo afirmar, com isso, que as identidades sejam "mais completas" ou mais "efêmeras" na vida real, ao contrário, defendo a idéia de que as identidades são constituídas de modo diferenciado. Nos chats, como ilustra o excerto acima, elas são mais breves, e aparentemente mais fáceis de serem constituídas intencionalmente naquele momento, para aquele estado de espírito, circunstância específica e interlocutor [como é o caso de inventar um corpo e um cabelo narrado no momento]; na vida real, a constituição das identidades parece demandar mais "trabalho" de construção, mais tempo de elaboração e expressão.

Referindo-se às culturas juvenis, Pais (1993) observa que as preferências musicais (o tema must de todos os chats) entre os jovens são acompanhadas de atitudes específicas que ultrapassam os gostos musicais como a escolha do vestuário, cortes de cabelo, frequiência a discotecas, pubs, bares onde predominam certos estilos de música etc. Também Valenzuela (1998) não vê a juventude como um conceito que possa ser entendido fora de seu contexto histórico e sociocultural; con- 
forme o autor, devido às transformações sociodemográficas e à propalada busca de "nivelamento" de desenvolvimento entre países - através da globalização o conceito de juventude inscreve-se através das características fundamentais da classe a que pertencem.

\section{Virtualidade e identidades: os chats abrem um campo para uma flutuação de identidades?}

Entre os vários enfoques com que a Internet tem sido analisada, a Rede tem sido especialmente focalizada no que diz respeito às identidades. Ela converteuse num "laboratório" para a realização de experiências com as construções e reconstruções do "eu" na vida pós-moderna, uma vez que, na realidade virtual, de certa forma moldamo-nos e criamo-nos a nós mesmos.

Para Turkle (1997), o ciberespaço ou espaço virtual, já prenunciado em filmes e romances de ficção científica, ${ }^{17}$ hoje em dia faz parte de nosso cotidiano. Quando trocamos e-mails ou conversamos com amigos em salas de bate-papo, além de estarmos nos deslocando por espaços e comunidades virtuais, podemos também adotar identidades "fictícias", criadas por nós mesmos. E elas podem variar conforme nossas contingências e circunstâncias do momento, interesses mediatos e imediatos, estados de humor, ou mesmo destinatários das nossas mensagens, ou seja, "nas comunidades em tempo real do ciberespaço encontramo-nos no limiar entre o real e o virtual, inseguros da nossa posição, inventando-nos a nós mesmos à medida que progredimos" (idem, p. 13).

A evolução tecnológica das práticas sociais nem sempre contradiz as culturas tradicionais nem as artes modernas, afirma Canclini (1998). O que se estabelece é uma "apropriação múltipla de patrimônios culturais $[\ldots .$.$] que acabam não só promovendo criati-$

${ }^{17}$ A série de filmes Guerra nas Estrelas pode ser citada como um dos primeiros exemplos de ficção científica de cibercomunidades em ciberespaços. Jogos de computador que simulam mundos virtuais, onde jogadores são convidados a criarem seu próprio mundo computadorizado organizando cenários e definindo regras, também são exemplos. Para maiores detalhes, ver Turkle, 1997. vidade e inovações mas também reproduzindo estruturas conhecidas" (p. 308-309). O autor ainda segue registrando - e acho pertinente citá-lo aqui - que a reorganização dos cenários culturais é permeada por constantes cruzamentos de identidades, as quais, por sua vez, exigem "olhares" acerca do que significa estar entrando e saindo da modernidade e as tensões de desterritorialização e reterritorialização. ${ }^{18}$ Canclini refere-se aos processos de "perda 'natural' da cultura em relação aos territórios geográficos e sociais e, ao mesmo tempo, a certas relocalizações territoriais relativas, parciais, das velhas e novas produções simbólicas” (p. 309). Hall (1997) nos aproxima mais desse mix cultural a que Canclini (1998) chama de hibridismo, assinalando que esses "deslocamentos" das culturas nos permitem comprar, gastar, olhar, poupar, escolher, conversar, socializar à distância, "virtualmente", de qualquer lugar para qualquer outro lugar através da Internet, associando "lugares" e locais e por que não - formando "comunidades imaginadas" ou virtuais. Nessas comunidades, relações se estabelecem através dos bate-papos, identidades se constituem, umas negociam com as outras, aproximam-se, identificam-se, atravessando distâncias geográficas reais, étnicas, na busca de similaridades "tribais" através de parâmetros como as audiências musicais; porque, como já afirmei, o grande mote das salas virtuais, blogs e webzines,$^{19}$ spam zines ${ }^{20}$ é a música (!)

${ }^{18}$ Cumpre notar que o termo desterritorialização foi introduzido por Gilles Deleuze e Félix Gattari e que, de acordo com Silva (2000b), "territorializar significa codificar, submetendo a regras controles setores ou elementos da vida social, como, por exemplo, a família, o trabalho, o corpo” (p. 38-39). Logo, nesse contexto, desterritorializar poderia significar a instituição de novas e renovadas regras ou mesmo o seu deslocamento.

${ }^{19}$ Webzine é a versão virtual de Fanzine - um tipo de revista na forma xerox, feita por universitários para divulgar festas, bailes etc. Depois foi incorporada por bandas de rap, funk etc. Consta que os fanzines nasceram junto aos estudantes da USP.

${ }^{20}$ Spam Zine é um fanzine distribuído por e-mail semanalmente. São crônicas, críticas, contos, análises, digressões, poe- 


\section{G eração N et? G eração Zapping? $Q$ ue tipo de juventude freqüenta chats?}

\author{
Eles querem fazer tudo ao mesmo tempo e \\ pertencem a várias tribos. Sabem lidar com o \\ excesso de informação, uma qualidade no \\ mercado fragmentado.
}

(Vannuchi \& Duarte, 2001)

O excerto citado, do texto de Vannuchi e Duarte intitulado "Geração Zapping", ${ }^{21}$ nos chama a atenção para o fato de que há uma juventude que convive, desde a infância, com a televisão, e que não consegue imaginar o mundo sem televisão, sem computador, sem Internet, sem chats, sem sites, sem celulares etc. É uma camada juvenil que tecla num chat ao mesmo tempo em que troca e-mails, navega em sites, assiste televisão [com o controle remoto à mão], ouve música num walkman ou num aparelho de som e comenta o que

mas, charadas, piadas, citações pop e comentários produzidos por uma equipe especializada. Veja mais no site: <http:// sites.uol.com.br/spamzine/oque01.htm>.

${ }^{21} \mathrm{O}$ termo zapping foi usado preferencialmente por Sarlo (1997), como a liberdade que um telespectador tem em usar seu controle remoto e trocar de canais incessantemente, numa velocidade que tem como efeito um enlace de imagens que dá a idéia de que estamos vendo uma imagem somente, ou seja, uma "montagem" feita pelo usuário do controle remoto. Conforme a autora, "no núcleo do discurso televisivo sempre existiu o zapping, como modo de produção de imagens encadeadas tirando partido da presença de mais de uma câmera no estúdio" (Sarlo, 1997, p. 60). Em nota, o tradutor da obra de Sarlo afirma que em espanhol "zapar, significa 'trabalhar com sapa' ou 'fazer trabalho de sapa' [...] termo que vem do italiano zappa, "enxada"” (ibidem, p. 60). Alguns autores (incluo-me nestes), apropriaram-se do termo zapping e o endereçaram também à noção de Geração Net (Net Generation) expressão utilizada primeiramente por Tapscott (1999) para categorizar aqueles que são usuários da Net em tempo quase integral, e que envolve uma espécie de zappear (navegar) em links, sites, blogs, em zonas virtuais, com a mesma velocidade com que se opera um controle remoto de televisão. assiste e ouve no chat em que tecla, troca de canais a todo instante em busca de novas imagens, de novos sons, dos mais diferentes lugares e com os mais diferentes personagens, com uma velocidade ímpar, inventando, com isso, novas cenas - no caso da televisão compondo assim uma espécie de fast-food de imagens acionadas por um controle remoto ou por um teclado.

Sarlo (1997), escrevendo sobre cenas da vida pósmoderna, assim argumenta sobre o ato de zappear:

Imagens demais e um dispositivo relativamente simples, o controle remoto, tornaram possível o grande avanço interativo das últimas décadas que não foi resultado de um desenvolvimento tecnológico da parte da grandes corporações, e sim dos usuários comuns e correntes. Trata-se é claro, do Zapping [...] o Zapping nos permite ler como se todas as imagens/frases estivessem unidas por um "e", um "ou", ou um "nem", ou simplesmente separadas por pontos. (p. 57 e 59)

Acredito que se pode relacionar o ato de zappear com o ato de teclar na Internet. Mãos que pulsam um controle remoto, mãos que digitam num teclado, zapeiam por sites, navegando incessantemente. Quando navegamos na Rede, abrimos uma porção de janelas e trabalhamos com muitas delas ao mesmo tempo, minimizando uma ou outra, compondo sketches em ritmos acelerados. Destarte, a abundância de informações tanto da Internet como da televisão provocam o ato de zapear, de buscar, de selecionar... Evidentemente, esta é uma parcela da juventude; um jovem que tem um computador pessoal e acessa a Internet é um jovem oriundo de uma classe economicamente mais privilegiada.

Para Tapscott (1999), de muitas maneiras a Geração Net/Zapping está formando vários tipos de comunidade na Internet. $\mathrm{O}$ autor assim comenta: "a Internet parece constituir-se em um veículo para exploração da individualidade e para que eles (crianças e jovens) se estabeleçam como indivíduos independentes" (p. 54). A interação que se estabelece nos chats requer que crianças e jovens desenvolvam valores, exercitem julgamentos, analisem, avaliem, critiquem ou venham a ajudar uma outra pessoa. 
É recorrente a afirmação de que a juventude atual substituiu os ideais mais amplos de mudança social e política por objetivos mais imediatistas, ligados ao prazer e ao consumo. A citação abaixo foi extraída de um blog da Rede e reflete um esforço de auto-reflexão, em que o autor partilha com outros jovens, leitores dos seus textos, suas angústias existenciais, suas incertezas sobre o seu "lugar", passando pelos alegados efeitos da mídia em sua vida:

\section{Quem sou...quem somos?}

Sou carne; Sou vida; Inteligência nova; e tragédia humana de sempre; Poeta frustrado; Jornalista incompleto, Certo da minha dúvida; Duvidoso das poucas certezas; Fruto do Atare [sic]; Herdeiro desgraçado das Xuxas e afins; Sou a eterna angústia adolescente; $\mathrm{O}$ medo e a expectativa do que está por vir. Um grito sufocado, uma gota de poesia que desliza entre meus dedos e cai na rede mundial $^{22}$

Relatos virtuais desse tipo - em que ecoa uma polifonia de vozes e discursos poéticos e prosaicos que circulam em nossa cultura - nos levam a refletir sobre a necessidade de pertencimento deste jovem e de outros jovens a algum lugar, a alguma coisa, a alguma crença, a alguma tribo. ${ }^{23}$ Nos últimos anos, as mudanças de identidades, sob o impacto cultural do computador conectado à Internet, parecem ter dado lugar a uma busca empenhada em entender e dar sentido aos mecanismos da vida real e virtual. O fato é que, se na vida cotidiana somos constrangidos por inúmeras "ordens de discurso" em que não revelamos determinadas facetas e emoções, na Internet, sob um nickname, atrás de uma tela e um teclado, outras "ordens de discurso" instituem-se e nelas é possível

${ }^{22}$ Citação extraída do blog denominado S/A Sociedade Amoral, <http://mentirassinceras.blogspot.com/ 2002_11_03_mentirassinceras_archive.html >.

${ }^{23}$ A noção de "tribo" está sendo utilizada neste trabalho com o sentido de agregações juvenis como "metaleiros(as)", "punks", "pagodeiros(as)" etc., que designam domínios, zonas de trânsito, territórios em disputa, onde imperam "outros" valores, "outras" leis. reconstruir nossas identidades como que do outro lado de um espelho, um espelho que nos solicita uma multiplicidade interior na maioria das vezes constituída e narrada por nossos interlocutores virtuais.

Por outro lado, sabe-se que o desenvolvimento das tecnologias dos computadores e da comunicação influenciou, e influencia, definitivamente as atitudes da chamada Geração Net. Aqueles que a sociedade, em seu afã de medicalizar e rotular comportamentos como normais ou desviantes, chama de "viciados" na Net, às vezes não conseguem sequer dormir, esperando por e-mails que podem chegar durante a noite, ou trabalham por horas sem parar no computador, sem fixar-se em horários (já apareceram muitas home pages de terapia para o "vício" da Internet). Por outro lado, Seo (2000) nos chama a atenção para o fato de que muitos jovens, às vezes, não estão protegidos contra as informações anti-sociais que são veiculadas na Rede, como por exemplo as relativas a pornografia, armas, violência, informações falsas, violência verbal na comunicação virtual etc. São jovens que têm amigos e vizinhos através da Internet. Não lhes interessa se estes vivem ao lado da sua casa ou do outro lado do mundo: são seus amigos virtuais, cibernéticos.

\section{Tribos juvenis da e na Internet}

$$
\begin{array}{r}
\text { Estar aqui, estar lá. Isso não parece ser muito } \\
\text { importante num chat entre jovens. Há uma } \\
\text { espécie de "identificação" primária, do tipo } \\
\text { "será que somos da mesma "tribo"? }
\end{array}
$$

Milhões de crianças e jovens ao redor do mundo, dentre aqueles que têm condições de ter acesso a um computador, estão neste momento conversando em chats online, ora para discutir um interesse comum, tal como esporte, guitarra, violão, grupos musicais, shows, ora sem nenhum propósito específico. Esta conversação passa pelo "querer estar com alguém" e interagir com outros da sua própria idade, às vezes até o "querer se conhecer pessoalmente". E é neste contexto que se afirma que está surgindo uma 
nova cultura jovem, "que envolve muito mais do que simplesmente cultura de música pop, MTV e filmes [...] é uma nova cultura no sentido mais amplo, definida como os padrões socialmente transmitidos e compartilhados de comportamento, costumes, atitudes e códigos tácitos, crenças e valores, artes, conhecimento e formas sociais" (Tapscott, 1999, p. 53). Ao invés de saírem para as ruas, shoppings, cinemas, parques, ou assistirem TV em suas casas ou nas casas de amigos, cada vez mais jovens estão se conectando ao seu computador e conversando com outros jovens, sejam companheiros de escola, bairro, sejam jovens de outras cidades, estados, países, enfim, de variados recantos do mundo.

É comum, nos chats, internautas entrarem e perguntarem: alguém aí quer conversar comigo?, como uma fórmula já corrente de abertura de espaço. Então, outra pessoa pode responder "sim", questionando o recém-chegado sobre o seu status: idade, gênero, uma descrição breve de onde mora, características físicas, como se parece, entre outras características. A pergunta primeira entre os gêneros masculino e feminino nos chats em geral basicamente é: como vc é? Qual a cor do seu cabelo? Qual sua idade? Vc é alta ou baixa, loira ou morena? Qual a cor da sua pele? Como é sua personalidade? - dentre outras similares. Mas nem sempre isso é tão importante.

Os chats preferidos pelos jovens acabam às vezes se tornando comunidades fechadas: estas são formadas quando um grupo de parceiros que conversam regularmente criam familiaridade um com o outro, formando uma espécie de "família" ou grupo fechado (os chats permitem que os internautas selecionem determinados(as) internautas e conversem entre si, formando um subgrupo de discussão que não permite acesso de outros) em torno da apreciação de alguma banda musical, cantor ou cantora preferido do qual outros internautas sentem-se excluídos, sendo ignorados (...) As salas de chats, como outras comunidades, não são livres de "desentendimentos", "desaforos", "desacatos", e de jogos de poder. As trocas de mensagens implicam mudanças nas relações no grupo e reafirmações de posição no grupo, como alian- ças, ataques, atos de diplomacia e atitudes machistas, assim como represálias a estas.

\section{Identidades e culturas; em direção a uma globalização cultural?}

Stuart Ewen, em seu livro Todas as imagens do consumismo, sugere que vivemos hoje sob a proteção de uma "política de estilo", ou seja, que a partir do estilo estaríamos construindo nossas marcas de distinção, nossas identidades, ocupando um lugar no mundo. Segundo Ewen (1991, p. 37), o estilo seria "o idioma do mundo das aparências em que vivemos", um mundo em que a experiência social estaria enfraquecendo. Para o autor, o estilo não estaria necessariamente balizado na experiência social, mas sim "atrelado" ao consumo e aos interesses do mercado.

Para discutir identidade e cultura hoje, sempre se fala em globalização cultural, ou mundialização da cultura. Diretamente relacionados com a questão da globalização, os processos de relocalizações sociais das novas e velhas produções simbólicas adquiriram importância no nosso cotidiano de final de século e início de outro. Canclini (1997a, 1997b, 1998), Sarlo (1997) e Margulis (2001), entre outros, destacam em suas obras a temática da "desterritorialização". Antes, as identidades estavam fortemente marcadas por questões de território - nações, regiões, bairros, clubes, escolas etc. Entretanto, a explosão da mídia e os processos de desterritorialização levaram a novas instâncias e marcas de produção de identidades.

De uma forma muito concreta, Margulis (2001), escrevendo sobre globalização e cultura, nos relembra que

[...] não apenas uma porção significativa dos bens que se consome são produzidos fora de cada nação, com as consequiências culturais implicadas nesta homogeneização dos produtos, sobretudo no plano dos processos culturais envolvidos na tendência à uniformização dos consumos; também as mensagens que se consome (meios de comunicação, publicidade) são, em boa proporção, produzidas fora do país. (p. 4) 
Resumindo: já que os jovens se constituem identitariamente através de uma "comunhão" de gostos e apreciações, a desterritorialização e o advento do rock um dos assuntos preferidos na Rede - favorecem identidades não mais relacionadas a bairros, clubes, regiões, nações... mas a um "estilo" que caracterizaria a representação dominante de "juventude".

Turkle (1997, p. 262) aponta para o sentido da "reterritorialização", decorrente da fragmentação da sociedade em que vivemos. Muitas das instituições (família, escola, rua, bairro, igreja etc.) que costumavam reunir e agrupar identitariamente as pessoas - a rua principal de uma localidade (ainda praticada em pequenas cidades do interior), a sede de um sindicato, de um clube, de uma associação de municípios já não cumprem a mesma função. Quantas pessoas com acesso à Internet passam horas dos seus dias diante da tela de computador, pesquisando, escrevendo $e$ mails, participando de listas de discussão, ou mesmo batendo papo com outras pessoas de outros lugares, tentando "retribalizar-se", interagindo com outros internautas enquanto mal conhecem seus vizinhos geográfica e espacialmente mais próximos? O que parece claro é que (incluo-me nestas comunidades) nosso enraizamento a um determinado lugar atenuouse, pois podemos "estar" em diversas partes do mundo, entrar e sair de grupos de discussão sem qualquer "prejuízo" real aparente.

Também podemos nos inspirar na afirmação de Canclini (1997b, p. 81), quando afirma que "necessitamos de enraizamentos em territórios, por mais desterritorializada que esteja a sociedade contemporânea; necessitamos referir-nos a indicadores de pertencimento que nos dêem segurança afetiva e clareza sobre os grupos com os quais podemos nos relacionar, com os quais podemos nos entender". Assim, se encontrei nos chats marcas dessa desterritorialização de que tanto se fala ao abordar a questão das identidades atualmente, também vislumbrei neles a busca de parceiros através de uma similaridade de conhecimentos e sentimentos, que, então, se tornam tópicos de extensas trocas e são esmiuçados detidamente. Tanto o gosto comum como o "desprezo" constituem eixos de identificação; a identidade, dizem os que hoje a estudam, se marca pela diferença.

\section{Locais virtuais e atividades de ócio, de lazer e identidades}

É importante salientar como os eixos de identificação em todos os chats analisados que aqui menciono estão relacionados de uma ou outra forma com o espaço de lazer, e não com espaços de obrigação "escola, estudo e, eventualmente, trabalho" (se é que os internautas trabalham, segundo uma concepção usual). A Internet e os chats localizam-se já neste espaço do lazer, e os tópicos neles tematizados também gravitam em torno do lazer, do "não-obrigatório". Nesse sentido, Feixa (1999) denomina de "atividades focais" a identificação subcultural que se concretiza na participação em determinados rituais e atividades próprias de cada estilo juvenil: a paixão por bandas grunges, o consumo de maconha em shows de rock, as idas aos bares, discotecas, os atuais points tribais em postos de gasolina, o teclar na Rede e discursar sobre seus ídolos ou execrar outros etc. Em territórios rurais ou de pequenos aglomerados urbanos, as paróquias, as praças, são também espaços de ócio. Nas ruas (quase toda cidade interiorana brasileira elege para isso uma rua/ avenida) em que se reúnem jovens nos finais de semana, bate-papos e caminhadas são constantes e nelas se ouvem gêneros musicais variados em alto volume. Saliento, assim, que as atividades comunitárias de lazer jovem não se restringem a grandes aglomerados urbanos, e que também nesses agrupamentos menores a música desempenha seu papel não apenas de diversão, mas identitário. Sem dúvida, não encontrei em nenhum chat de música algum internauta que lá estivesse "contra" a sua vontade. $\mathrm{Li}$, sim, muitas vezes, manifestações como: Tenho que me retirar pq tenho aula cedinho! Ai que óóóóóódioooooooooooo!

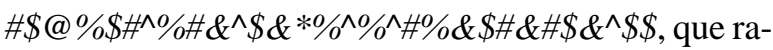
tificam a posição de que bater papo na Rede, falar sobre música, rever amigos, fazer novos, ou mesmo "brigar", é sempre algo eletivo, buscado e nunca "forçado", compulsório. Fato evidente é que os jovens 
buscam muito mais os espaços de lazer do que os(as) adultos (talvez, também, por desfrutarem de mais tempo "livre"...). Além do mais, tais espaços aparecem como um lugar onde se pode desfrutar de certa autonomia, em contraste com a autoridade adulta dominante em outras esferas da vida dos jovens (família, escola, trabalho).

Privados, às vezes, de um espaço próprio [entenda-se que falo não apenas de espaço no sentido físico] dentro de suas próprias casas, estes espaços de ócio - incluindo aqui a Internet - com os amigos, a música, os bate-papos sobre música, enfim, configuram um clima caloroso, "familiar".

\section{E no fim das contas... 0 que interessa pra nós? ${ }^{24}$ Em direção às considerações finais}

Mesmo que a Internet aqui no Brasil ainda esteja "na infância", as narrativas nela veiculadas não o são. Logo, quando se trata de culturas juvenis e identidades constituídas na Rede, em salas de bate-papo, listas de discussões sobre os mais variados assuntos, sites, blogs, enfim, neste caleidoscópio que é a Rede, não é possível deixar de ratificar a idéia de que as culturas juvenis são o resultado de condições de possibilidade que se criam a partir dos discursos na e $d a$ Rede, e isso constitui identidades. Trago novamente Hall (2000) quando observa sobre as identidades: "elas emergem no interior do jogo de modalidades específicas de poder e são, assim, mais o produto da marcação da diferença e da exclusão do que do signo de uma unidade idêntica, naturalmente constituída, de uma 'identidade' em seu significado tradicional [...] sem costuras, inteiriça, sem diferenciação interna" (p. 109), ou seja, as identidades são construídas através, e não fora das diferenças. Estas afirmativas ratificam os achados: há deslocamentos, deslizamentos, "influências" de grupos, resistências... Resgato, a seguir, algumas inquietações que foram "marcadas" na

${ }^{24}$ Frase extraída da canção Pintura Íntima, da banda Kid Abelha \& os Abóboras Selvagens. escrita deste artigo, recorte de estudo anterior sobre identidades musicais juvenis na Rede.

\section{O s discursos na Internet são representações ou criação de identidades?}

É consensual que as comunidades virtuais constituídas na Internet abrem um campo para uma flutuação de identidades, mas, ao mesmo tempo, verifica-se um trânsito de difícil definição, entre as identidades "dentro" e "fora" da Rede. É cada vez mais freqüente nos últimos anos circularem na mídia internacional e nacional notícias sobre casos de relacionamentos que se iniciaram na Internet e terminaram em assassinatos, seqüestros, enganos, ou casos amorosos. Abro o exemplar de um jornal e leio na primeira página: Briga fatal começou em chat da Internet (Jornal Zero Hora, 11 mar. 2003). Na sequiência de notícias, nos dias que se seguem ao episódio, leio excertos de chats entre amigos do jovem assassinado, que de certa forma ratificam a inimizade, troca de insultos e desfecho trágico, que teria se iniciado na Internet, numa sala de batepapo do IRC (Internet Relay Chat). As notícias que se seguem ao desfecho relatam que a "briga real" teria se iniciado em um chat da Rede, no qual o suspeito dizia ser lutador de jiu-jitsu e, através do nickname, vinha ameaçando a vítima também pelo suposto fato de que o garoto morto estaria "roubando" a namorada "real" do suposto agressor. Ou seja: um tipo de relacionamento virtual que tem continuidade na vida real com toda a hierarquia de demandas exigidas nesta. É cada vez mais comum o início de inimizades em chats que terminam em desentendimentos (quando não em tragédias) na vida real, num trânsito entre o virtual e o "real", em que este último empresta concretude ao real. Exemplifiquei com detalhes esse episódio recente de modo a ilustrar as afirmações de Turkle (1997) quando escreve que:

\footnotetext{
[...] na história da construção da identidade na cultura da simulação, as experiências na Internet ocupam um lugar de destaque [...] e esse contexto é a história da erosão das fronteiras entre o real e o virtual, o animado e o inanimado, o eu
} 
unitário e o eu múltiplo, que está ocorrendo tanto nos domínios da investigação científica de ponta como nos padrões da vida quotidiana. (p. 12)

\section{D iscursos e identidades}

Muitas das inquietações que assolam os estudiosos de estudos culturais podem ser sintetizadas na questão de Culler (1999, p. 111): "O discurso representa identidades que já existem ou as produz?” Minha resposta é de que simultaneamente as identidades são representadas e se constituem incessantemente nas conversas, nas perguntas e comentários que constroem posições de sujeito para os internautas. Todos sabemos o quanto nossa imersão em comunidades reais de trocas discursivas, usos de linguagem, enfim, afeta nossas histórias, nossas “visões", nossas "percepções". Por que isso não ocorreria nos chats? Entendo, portanto, que minha resposta à questão de Culler é de que simultaneamente acontecem ambas as ações e, como afirma Hall (2000), as identidades são construídas através, e não fora da diferença, e são o resultado de uma bemsucedida articulação ou "encadeamento" do sujeito no fluxo discursivo. Trago o pensamento de Larrosa (1996) em relação à sua visão de identidade: "quem sou não é algo que progressivamente encontro ou descubro ou aprendo a descobrir melhor, e sim algo que fabrico, que invento e que construo no interior dos recursos semióticos de que disponho, do dicionário e das formas de composição que obtenho das histórias que ouço e que leio, da gramática; em suma, que aprendo e modifico nessa gigantesca e polifônica conversação de narrativas que é a vida" (p. 477).

Entendo que, além de todos os sentidos prévios de pertencimento que os jovens internautas levam aos chats, de suas representações sobre "quem são", há toda uma constituição de identidade que também acontece nessas conversas dos chats. Relembro Hall (2000), ao afirmar, em relação às identidades, que "é precisamente porque as identidades estão construídas dentro e não fora do discurso que nós precisamos compreendê-las como produzidas em locais e contextos históricos e institucionais específicos, no interior das formações e práticas discursivas específicas, produzidos por determinadas estratégias discursivas" (p. 109). O autor observa ainda que "elas emergem no interior do jogo de modalidades específicas de poder e são, assim, mais o produto da marcação da diferença e da exclusão do que do signo de uma unidade idêntica, naturalmente constituída, de uma 'identidade' em seu significado tradicional [...] sem costuras, inteiriça, sem diferenciação interna" (p. 109), ou seja, as identidades são construídas através, e não fora das diferenças. Estas afirmativas ratificam os achados a cada visita na Rede: há deslocamentos, deslizamentos, "influências" de grupos, resistências...

\section{As identidades na Internet são mais "fictícias" do que as outras?}

A utilização dos nicknames é, na minha opinião, um dos grandes marcadores identitários da Internet. É uma das principais características que têm sido associadas à questão das identidades virtuais e podem ser vistos como uma das suas principais marcas. Turkle (1997) argumenta que a Internet é um elemento do computador que contribui para encararmos a identidade como multiplicidade. Através da tela de um computador tem-se a possibilidade de construir uma "personalidade" alternando entre muitas outras. Alguns internautas, em entrevistas à autora, descrevem-se como "viciados na mudança permanente", ou que "podem inventar seu nome quantas vezes quiserem"... As alternâncias entre diferentes identidades possibilitadas pelo uso da Internet, através de chats, de certa maneira desconstroem a metáfora da "solidez" da identidade, e se, há algumas décadas, falavase que as pessoas assumiam diferentes papéis na sociedade, na maioria dos casos isso significava que, mesmo assim, mantinham os laços vitalícios com uma determinada família e comunidade. Mesmo que um suposto controle abrisse algumas brechas eventualmente, tais identidades situavam-se às margens da sociedade ou eram vistas como uma "alternância" de vida ou a chamada "personalidade desdobrada". $\mathrm{Na}$ era pós-moderna, as identidades múltiplas perderam grande parte de seu caráter "marginal". Muitas pessoas apreendem a identidade como um conjunto de 
posições de sujeito que podem ser misturadas e acopladas. Abaixo, alguns exemplos de nicknames extraídos de uma sala de bate-papo destinada à faixa etária de 11 a 15 anos:

Excerto $n^{\circ}$ 6, extraído do Portal UOL/março de 2003

(23:37:34) O K-R@DO SOM grita com Gato_Barra_ICQ

(23:37:42) óGatinho_só do cs fala para P@ty

(23:37:49) ®AHTAH@ fala para §h@ @ •\$p•@ •

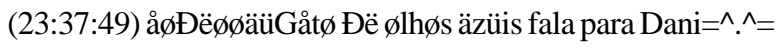
$(23: 37: 57) i^{\circledR \wedge} \mathrm{A}^{\wedge} \mathrm{nJo}{ }^{\circledR e B e L d E}$ fala para *Amo o tom Delong*

(23:38:08) Diabo Loiro 17 Sem Mulher com icq grita com TODOS

$(23: 38: 59) \dagger ; £$ all??_†?G?;£*d: entra na sala...

(23:39:27)

(23:39:29) o arrazador das gatinhas fala para * a gatinha *

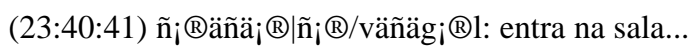

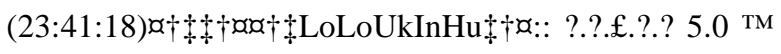

[MFJFFGEECMLB4EHCACDI2M]:: entra na sala... (00:06:03) **LOLIT@** fala para BOM!:

Nicks estranhíssimos, com grafias ilegíveis, alguns com jogos de vogais, consoantes e símbolos, que passam a idéia de um grafite $^{25}$, outros com demonstração de sentimentos, desejos, estados de ânimo, outros com nomes próprios, simplesmente... enfim, se na vida cotidiana nossos nomes não foram por nós escolhidos, e sim atribuídos por nossos pais, a Internet oferece uma possibilidade ímpar de exercitarmos escolhas, e escolhas que podem se modificar a cada "teclada", a cada encontro virtual, funcionando assim como marcadores cruciais de identidades. De qualquer sorte, "entrar como" - expressão freqüente para os(as) jovens internautas se referirem à adoção do nickname - pode ser lido, como "estar, neste momento, como..."

Assim, nestas últimas linhas, retomo a noção de que numa comunidade virtual, seja ela um chat, uma

25 "Desenhos coloridos e densos, feitos nos espaços públicos das cidades" (Herschmann, 2000, p. 288). lista de discussão, um blog coletivo, onde há troca de discursos entre interlocutores, onde podemos encarar nossas identidades com muito mais multiplicidade, onde podemos nos inventar do jeito que quisermos e nos sentirmos naquele momento, naquele lugar, as identidades são, sim, fictícias, porém não menos que as da vida real. São apenas diferentes, mais breves, talvez mais flexíveis que as do cotidiano real. Concordo com Woodward (2000) quando afirma que a identidade é relacional, depende, para existir, de algo fora dela, isto é, de outra identidade, logo, é marcada pela diferença. Se Hall (2000) argumenta que precisamos entendê-las como produzidas em locais específicos, ratifico a idéia de que a Internet passa a ser um desses locais onde jovens constituem e são constituídos identitariamente, através de seus discursos e visuais descritos virtualmente. Se suas idades, seus atributos físicos, seus gostos, seus gêneros, suas preferências sexuais, enfim, são verdadeiras ou não, isso não nos interessa, porque as identidades são marcadas pela invenção, "elas têm a ver [...] com a questão da utilização dos recursos da história [de cada um], da linguagem e da cultura para a produção não daquilo que somos nós, mas daquilo no qual nos tornamos" (Hall, 2000, p. 109, grifos meus). Logo, o excerto citado anteriormente, extraído de um blog no qual o jovem se pergunta: "Quem sou eu?, Quem somos? [...] Sou a eterna angústia adolescente", nos endereça ao que Hall denomina de "chamamento do sujeito pelo discurso - 'interpelação' - [...] toda a identidade tem necessidade daquilo que lhe 'falta' mesmo que esse outro que lhe falta seja um outro silenciado e inarticulado" (idem, p. 110).

O mais raro de se encontrar na Rede são "corpos dóceis" no sentido foucaultiano, porque se o corpo é construído e moldado segundo discursos (disciplinares), na Internet eu simplesmente "teclo" e invento um corpo "sarado", desejável; invento uma altura, um tipo de cabelo, uma cor de olhos, um bronzeado, enfim, constituo-me temporariamente por narrativas de acordo com os padrões para aquele determinado momento e interlocutor. É fictício? Sim, é, mas quem de nós, na vida real, ao ver seu corpo refletido num espelho, ao ouvir sua própria voz (gravada ou não), ao reler um texto seu, 
não se inventou diferente? Constituiu-se e deixou-se capturar pelo discurso da ordem do dia (pela "ordem do discurso"?), mesmo que por poucos segundos?

Assim é na Internet: constituições discursivas temporárias, sem suturas, porém com marcação de fronteiras, carregadas de diferenças, como na vida real... - Você já tentou navegar na Internet? Entrar em algum chat e bater algum papo? Experimente...

ELISABETE MARIA GARBIN é doutora em educação pelo Programa de Pós-Graduação em Educação da Universidade Federal do Rio Grande do Sul, autora da tese intitulada www.identidadesmusicaisjuvenis.com.br; um estudo de chats sobre música da Internet. Atua como docente na Faculdade de Educação da UFRGS. Além de trabalhar com as disciplinas didática geral e educação musical, vem realizando estudos sobre juventudes, identidades, música, Internet e afins, atuando como pesquisadora do Núcleo de Estudos sobre Currículo, Cultura e Sociedade (NECCSO), desenvolvendo o projeto "Música e identidades juvenis; possibilidades etnográficas pós-modernas”. Publicou, recentemente: em coautoria, Identidades musicais juvenis nos chats da Internet, no Boletin de Investigación Educativo-Musical do Centro de Investigación en Educación Musical del Collegium Musicum de Buenos Aires (dez. 2002; Escribiendo, hablando y gritando en los chats de Internet: el lenguaje de la Generación Net, nos Anais do VII Congreso Latinoamericano para el Desarrollo de la Lectura y la Escrita (México-DF: Editora Direción General de Materiales y Métodos Educativos de la Subsecretaría de Educación Básica y Normal, out. 2002; Adolescência, Música e Identidades (CD Rom do IV Seminário de Pesquisa em Educação da Região Sul/Anped, nov. 2002). E-mail: emgarbin@terra.com.br; Site: www.ufrgs.br/neccso

\section{Referências bibliográficas}

BROKER, P., (1998). A concise glossary of the cultural theory. New York: Arnold.

CANCLINI, Néstor García, (1997a). Consumidores e cidadãos conflitos multiculturais da globalização. $3^{\mathrm{a}}$ ed. Rio de Janeiro: Editora UFRJ.

, (1997b). Cultura y comunicación: entre lo global y lo local. Universidad de La Plata. La Plata, Provincia de Buenos Aires: Ediciones de Periodismo y Comunicación, ${ }^{\circ} 9$.
, (1998). Culturas híbridas: estratégias para entrar e sair da modernidade. São Paulo: EDUSP. Tradução de Ana Regina Lessa e Heloísa Pezza Cintrão.

CULLER, Jonathan, (1999). Teoria literária - uma introdução. São Paulo: Beca. Tradução de Sandra Guardini T. Vasconcelos.

EWEN, Stuart, (1991). Todas las imágenes del consumismo - la política del estilo en la cultura contemporánea. México: Grijalbo.

FEIXA, Carlos, (1999). De jóvenes, bandas y tribus - antropologia de la juventud. Barcelona: Ariel.

FERREIRA, Paulo Henrique, (2003). Pura diversão. In: Tecnologia da informação-new media. Disponível em: <http://www.bigbiz.com.br/ newmedia/041102.htm>. Acesso em: 16 mar. 2003.

GARBIN, Elisabete Maria, (2001). www.identidadesmusicaisjuvenis.com.br - um estudo de chats sobre música da internet. Tese de Doutorado. Faculdade de Educação da UFRGS.

HALL, Stuart, (1997). A centralidade da cultura: notas sobre as revoluções de nosso tempo. Educação e Realidade, Porto Alegre, FACED/UFRGS, v. 22, n² 2, p. 15-46, jul./dez. , (1998). A identidade cultural na pós-modernidade. $2^{\mathrm{a}}$ ed. Rio de Janeiro: DP\&A. Tradução de Tomaz Tadeu da Silva e Guacira Lopes Louro.

(2000). Quem precisa de identidade? In: SILVA, Tomaz Tadeu (org.). Identidade e diferença; a perspectiva dos estudos culturais. Petrópolis: Vozes. p. 103-133.

HERSCHMANN, Micael, (2000). O funk e o hip-hop invadem a cena. Rio de Janeiro: Editora UFRJ.

INTERNET NEY, (2003). [weblog]. Frequently asked questions. Disponível em: <http://www.interney.net/blogfaq.php>. Acesso em: 20 mar. 2003.

KID ABELHA \& OS ABÓBORAS SELVAGENS, (1984). In : Seu espião. Rio de Janeiro: Faixa/Pintura Íntima.

LARROSA, Jorge, (1996). Narrativa, identidad y desidentificación. In:__ La experiencia de la lectura. Barcelona: Laertes.

MARGULIS, Mário, (2001). Globalización y cultura. Instituto de Investigaciones Gino Germani, Facultad de Ciencias Sociales, Argentina: Universidad Buenos Aires. Disponível em: <http:// www.fsoc.uba.ar/Publicaciones/Sociedad/Soci09/margulis.html>. Acesso em: 16 mar. 2001. 
NAGAKI, Alexandre, (2003). Pensar enlouquece. Pense nisto (Weblog). Disponível em: <http://www.inagaki.blogger.com.br/ 2002_10_01_archive.html>. Acesso em: 29 mar. 2003.

NEGROPONTE, Nicholas, (1995). Vida digital. São Paulo: Companhia das Letras. Tradução de Sérgio Tellaroli.

O'SULLIVAN, Tim et al., (1997). Conceptos clave en comunicación y estudios culturales. Buenos Aires: Amorrortu. Tradução de Alcira Bixio.

PAIS, José Machado, (1993). Culturas juvenis. Lisboa: Imprensa Nacional da Casa da Moeda. (Colecção Análise Social).

PATROLA, (2003). Porto Alegre: RBS TV, 8 mar. 2003. Programa Televisivo destinado ao público juvenil.

RÁDIO NEDERELAND, (2003). [Weblog]. Salan Pax. Disponível em: <www.dear_raed.blogs-pot.com e www.rnw.nl/sp/ toolbar/librostart.html>. Acesso em: 20 mar. 2003.

SAPO PORTUGAL, (2003). [Weblog]. Disponível em: <http:// sonhando.no.sapo.pt/sonho33.html>. Acesso em: 30 mar. 2003.

SARLO, Beatriz, (1997). Cenas da vida pós-moderna: intelectuais, arte e vídeo-cultura na Argentina. Rio de Janeiro: Editora UFRJ. Tradução de Sérgio Alcides.

SEO, Yoon Bong, (2000). Dos frutos de la era cibernética: la generación net y los hackers. Universidad de Guadalajara, 8p. Disponível em: <http://fuentes.csh.udg.mx/CUCSH/ Sincronia/ joon.htm>. Acesso em: 26 set. 2000.

SILVA, Tomaz Tadeu (org.), (2000a). A produção social da identidade e da diferença. In: Identidade e diferença : a perspectiva dos estudos culturais. Petrópolis: Vozes. p. 73-102. , (2000b). Teoria cultural e educação: um vocabulário crítico. Belo Horizonte: Autêntica.

SPAM ZINE, (2003). [Weblog]. O que é spam Zine? É de comer? Disponível em: <http://sites.uol.com.br/spamzine/oque01.htm〉. Acesso em: 25 mar. 2003.

SPOT SOCIEDADE AMORAL, (2003). [Weblog]. Disponível em: <http://mentirassinceras.blogspot.com/ 2002_11_03_mentirassinceras_archive.html>. Acesso em: 26 mar. 2003.

TAPSCOTT, Don, (1999). A crescente e irreversível ascensão da geração net. São Paulo: Makron Books. Tradução de Ruth Gabriela Bahr.
TERRA, (2003). Portal de internet Terra. Disponível em: <http:/ /www.terra.com.br>. Acesso em: maio/2001 e março/2003.

TURKLE, Sherry, (1997). A vida no ecrã; a identidade na era da internet. Lisboa: Relógio D’Água Editores. Tradução de Paulo Faria.

\section{UNIVERSIDADE FEDERAL DO RIO GRANDE DO SUL, (2003).}

Faculdade de Educação, Programa de Pós-Graduação em Educação, Núcleo de Estudos sobre Currículo, Cultura e Sociedade. Disponível em: 〈http://www.ufrgs.br/neccso>. Acesso em: 30 mar. 2003. Coordenação de Marisa Vorraber Costa.

UNIVERSIDADE FEDERAL DO RIO GRANDE DO SUL. Faculdade de Educação, Programa de Pós-Graduação em Educação, (2003). Projeto Integrado de Pesquisa: textos, discursos e identidades em educação. Disponível em: <http:// www.ufrgs.br/pitdre>. Acesso em: 31 mar. 2003. Coordenação de Rosa Maria Hessel Silveira.

UNIVERSO ONLINE, (2003). Portal de internet UOL. Disponível em: <http://www.uol.com.br>. Acesso em: maio/2001, mar./ 2003.

VALENZUELA, José Manuel, (1998). Identidades juveniles. In: CUBIDES, Humberto J., TOSCANO, María Cristina Laverde, VALDERRAMA, Carlos Eduardo H., (ed.). Viviendo a toda; jóvenes, territorios culturales y nuevas sensibilidades. Fundación Universidad Central, Santafé de Bogotá: Paidós (Série Encuentros).

VANNUCHI, Camilo, DUARTE, Sara, (2001). Geração zapping. Veja, São Paulo, n 1659, p. 82-87, 18 jul.

WOODWARD, Kathryn, (2000). Identidade e diferença: uma introdução teórica e conceitual. In: SILVA, Tomaz Tadeu (org.). Identidade e diferença; a perspectiva dos estudos culturais. Petrópolis: Vozes. p. 7-72.

ZERO HORA, (2003a). Porto Alegre (RS), ano 39, $n^{\circ} 13.716,2^{\mathrm{a}}$ ed., terça-feira, 11 mar., p. 4-5. , (2003b). Porto Alegre (RS), ano 39, $n^{\circ} 13.730,2^{\text {a }}$ ed., domingo, 25 mar., p. 6. , (2003c). Porto Alegre (RS), ano 39, $\mathrm{n}^{\circ} 13.729,2^{\mathrm{a}}$ ed., segunda-feira, 24 mar., Suplemento ZH Escola, p. 1-3.

Recebido em março de 2003 Aprovado em março de 2003 